\title{
Post-COVID-19 Sustainable Waste-to-Energy Solutions for Uganda's Displacement Camps: A Review
}

\author{
Reuben Gad Mugagga ${ }^{1, *}$, Hope Baxter Chamdimba ${ }^{2}$ \\ ${ }^{1}$ Energy Technology Department, School of Engineering, Kenyatta University, Nairobi, Kenya \\ ${ }^{2}$ Energy Resources Department, Ndata School of Climate and Earth Sciences, Malawi University of Science and Technology (MUST), \\ Thyolo, Malawi
}

Email address:

gadrobben@gmail.com (R. G. Mugagga), hbchamdimba@gmail.com (H. B. Chamdimba)

${ }^{*}$ Corresponding author

\section{To cite this article:}

Reuben Gad Mugagga, Hope Baxter Chamdimba. Post-COVID-19 Sustainable Waste-to-Energy Solutions for Uganda's Displacement Camps: A Review. International Journal of Sustainable and Green Energy. Vol. 10, No. 2, 2021, pp. 32-39. doi: 10.11648/j.ijrse.20211002.11

Received: March 31, 2021; Accepted: April 19, 2021; Published: April 29, 2021

\begin{abstract}
The launching of the Sustainable Development Goals in 2015 has continually advanced the sustainability paradigm across all corners of the globe. While this has led to the fruition of inherent country policies and plans for Uganda, the country is still trailing below the desired rate of attaining SDGs by 2030. The commencement of this decade of action and the proliferating intensity of the current unprecedented health crisis have thus called for heightened emphasis on inclusive sustainable development for the most disproportionately disadvantaged populations of which refugees form part. The pandemic has forced key stakeholders to shift their focus by re-allocating their scarce resources from disadvantaged communities such as refugee camps, thereby exposing them to severe and unacceptable vulnerability. Coupled to this COVID-19 pandemic is the prevalent energy crisis in displacement camps which shall have far-reaching disruptions. Increased energy access in refugee settlements shall help advance the modest progress made so far. This paper therefore highlights the most promising Waste-to-Energy (WtE) options for displacement camps in the Ugandan context which are evaluated based on a Multi Criteria Decision Analysis (MCDA) matrix upon which deductions of anaerobic digestion and briquettes respectively serve as the best ranked options respectively for more inclusive social economic development in these settings.
\end{abstract}

Keywords: Inclusive Sustainable Development, Refugees, Renewable Energy, Uganda, Waste to Energy

\section{Introduction}

Upon the launching of the Sustainable Development Goals (SDGs) in 2015, a global urgency towards social, economic and environmental progression was envisaged for the better well-being of humanity and the planet by 2030 [1]. This therefore served as the inspiration for immediate adoption of these SDGs by United Nations (UN) member states, of which Uganda is party. Uganda was one the first countries globally to embrace and domesticate the 2030 Agenda by integrating and mainstreaming its principles into the National Development Plan II (NDP II) [2]. This plan remained pivotal alongside its' integral consortium of national planning and development frameworks as its overarching goal was to propel the country to lower- middle income status by 2020 . This establishment further paved way for the structural operationalization towards the realization of sustainable development by emphasizing the need for planning, partnerships, co-ordination and reporting [3]. Progressively, a National Standard Indicator (NSI) Framework was developed which featured the mapping of specific NSIs in line with the mapped SDGs targets so as to serve as a useful benchmark for monitoring, reporting and accountability $[2,4]$.

To date, the country is still faced with wide spread regional income inequalities which stands as a key indicator leading to incoherent, uneven and delayed progress of the SDGs [1, 5]. Through the timely reviews for both the National Development Plan II (NDP II) and the Voluntary National Review (VNR) of the 2030 Agenda, the government further seeks to improve household incomes and quality of life for its population [4-6]. Therefore, building upon the previous plans, a more programmatic planning approach has been fronted so as to fast track sustainable economic 
transformation [5]. Notably, the commencement of this decade of action calls for more solidarity, political will and more ambitious action of key stakeholders through inclusive and dedicated transformative pathways [1] most especially in the wake of the novel corona virus disease (COVID-19) whose ramifications could remain a major deterrent to the achievement of the UN SDGs in the most vulnerable populations like the refugees.

The call for Inclusive Sustainable Development (ISD) in any country demands equitable consideration of the pre-eminent socio-economic challenges faced by the populace including people in displacement camps in respect to our shared future. In these camps, refugee self-reliance remains of utmost importance in the achievement of social-economic inclusion of the displaced people [7]. Uganda is currently a host to $1,450,317$ refugee and asylum seekers whose countries of origin are prone to civil wars and other catastrophes [8]. With over 14 displacement camps (figure 1), the country therefore is host to the largest refugee population on the continent and ranks the third globally after Turkey and Pakistan [7,9] yet this number is anticipated to grow to $1,562,465$ by the end of 2021 [10].

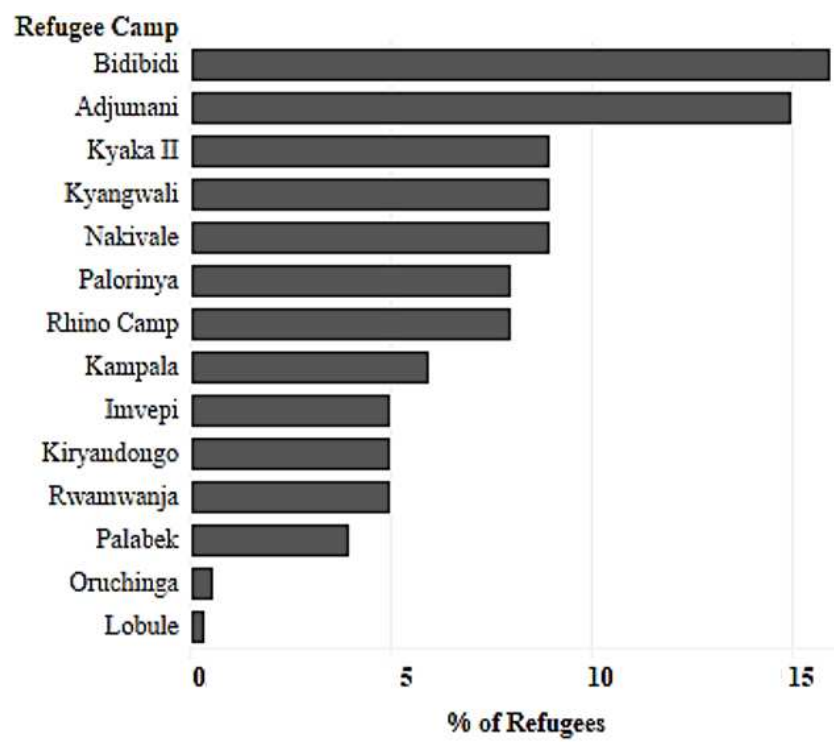

Figure 1. Refugee percentages per Camp in Uganda. [11]

Underpinning these ISD efforts, is the country's refugee integration model that is hailed for being the most inclusive and progressive among refugee policies globally [12]. Inadvertently, the country's refugee integration model has attracted numerous distressed refugees from its neighbors. This unprecedented number of refugees is having severe ramifications on the host communities, environment and the refugees themselves due to the intensified scramble for scarce resources like food, energy, water, shelter and sanitation in the now host nations thus exposing them to a more fragile crisis [13].

Amidst these COVID-19 challenges therefore, this paper seeks to discuss energy poverty implications in refugee camps of Uganda and the impact of policies, regulatory frameworks and global agendas on the provision of sustainable energy through WtE in the post-COVID 19 era. This paper is organized as follows; section 2 emphasizes the impact of COVID-19 in the Ugandan refugee camps while the subsequent section highlights the existing in-line policies that could spearhead positive change going forward. This is then followed by section 4 that presents challenges currently faced in these displacement camps. In section 5, emphasis is placed on energy as an enabler for ISD with an in-depth evaluation of sustainable WtE solutions through the MCDA in the next section. Lastly, the conclusion and recommendations are then discussed with respect to the proposed best ranked solutions.

\section{COVID-19 Impact and the Refugee Status}

The magnitude of this unprecedented crisis continues to inevitably deter and turn back decades of the progress achieved thus far with regard to SDGs in a more excruciating manner for the worlds' poorest and vulnerable populations if un-attended to. With the latter population consisting mainly of refugees, the implications of this crisis are and shall have far reaching consequences in Uganda as they have compounded the continued threat of climatic shocks, the locust crisis and the emergent conflicts [1]. A more recent survey involving 2,010 respondents conducted by Atamanov et. al. showed that the employment rate reduced to $43 \%$ while poverty, food insecurity and the in accessibility to social services increased to $52 \%, 85 \%$ and $80 \%$ respectively [14].

Table 1. Refugee and asylum population

\begin{tabular}{llll}
\hline $\begin{array}{l}\text { Country of } \\
\text { Origin }\end{array}$ & $\mathbf{2 0}^{\text {th }} \mathbf{F e b , 2 0 2 0}$ & $\mathbf{3 1}^{\text {st }} \mathbf{J a n , ~ 2 0 2 1}$ & $\begin{array}{l}\text { Percentage } \\
\text { Increase (\%) }\end{array}$ \\
\hline South Sudan & 873,741 & 890,854 & 0.020 \\
DRC & 409,882 & 422,989 & 0.032 \\
Burundi & 48,119 & 49,688 & 0.033 \\
Somalia & 40,181 & 44,982 & 0.119 \\
Rwanda & 17,383 & 17,956 & 0.033 \\
Eritrea & 14,912 & 16,567 & 0.111 \\
Sudan & 3,165 & 3,318 & 0.048 \\
Ethiopia & 3,047 & 3,253 & 0.068 \\
Others & 668 & 710 & 0.063 \\
TOTAL & $1,411,098$ & $1,450,317$ & 0.028 \\
\hline
\end{tabular}

Source: $[8,15]$

Irrespective of the travel restrictions imposed during this crisis, there has been a continued refugee influx in the country mainly from Somalia and Eritrea (each accounting for over a $10 \%$ increase) (Table 1). Similarly, up to about 30 refugees per day continued to proliferate into Bidi-Bidi displacement camp which is located in West Nile [16]. Consequently, the growing numbers of refugees has intensified the scramble for social services in the country $[13,17]$ which was already wanting even before the COVID-19 crisis. On one hand, energy remains critical as it is both a basic need and an essential in meeting day to day needs in refugee camps with regard to heating, cooking and lighting [13, 18] whereas on the other, proper sanitation is also regarded as a basic human right [19]. 
This pandemic shall exacerbate the brunt of the refugees the more as it parallels the existing protracted crisis characterized with their ever increasing populations which even at a bare minimum fail to adhere to the guidelines and protocols spelt out by the World Health Organization (WHO) for reduced virus spread. Therefore, in line with achieving the global commitment of leaving no one behind, it is imperative to specifically address the domestic energy needs of the displaced with regards to cooking and lighting predominated by scarce fuel wood and charcoal [20]. The existential threat of COVID-19 continues to far outweigh other diseases outbreaks like cholera and diarrhoea brought about by improper sanitation in these camps [21]. Therefore, to avert the current and impending ramifications of the virus on the health sector, collective pragmatic efforts by concerned stakeholders shall be necessary.

\section{Related Policy, Regulatory Frameworks and Global Agendas}

Uganda's policies and regulatory frameworks formulated in the post 2030 Agenda are premised on the global agendas as the country has always sought to domesticate these provisions. For instance, the 2030 agenda has been localized through different policies and NDPs which among others seek to improve living standards people [6]. However, widening income inequality remains a fundamental challenge which the government through the current NDP III seeks to reduce by $7.32 \%$ by the year 2025 [5]. This implies the cultivation, shaping and full implementation of all schemes geared towards the more vulnerable populations for more genuine social and economic progress so as to allow for transformative inclusion which entails consideration of refugees into national statistics too.

With regard to the refugees, these efforts shall be anchored on both the Refugee Act of 2006 and Refugee Regulations of 2010. Further policy articulation is conveyed in the current Comprehensive Refugee Response Framework (CRRF) founded with the major emphasis based on refugee self-reliance [22]. This has not been the case thus far [10]. However, through strategic design and implementation of prioritized sector plans and policies, the shared burden and responsibilities amongst related line ministry frameworks shall provide for better diversity and inclusivity for more transformative pathways.

In building the necessary resilience with regards to SDGs in displacement camps, strong sector collaborations through more robust inter-linkages shall be of essence going forward with the current challenges posed by the COVID-19 crisis. Furthermore, while priority is being channeled to the containment of the spread of the virus, critical focus on provision of clean and affordable energy ought not to be overlooked so as to uphold the efforts stressed in the overarching international SDG 7 that is currently supported by the Sustainable Energy for All Agenda (SE4ALL), UNHCR Global Strategy for Sustainable Energy 2019-24, Water and
Environment Sector Refugee Response Plan (WESRRP) 2019, Draft National Energy Policy 2019, Uganda Vision 2040 and the Safe Access to Fuels and Energy Strategy 2016-2020 among others.

Though the disruptions of the current pandemic have taken precedence with more resources being diverted to health sector, the displaced should remain at heart while dealing with exclusion upon which sustainability is concretized to a given extent. Therefore in the post- pandemic era, cohesive and inclusive inter linkages of the existent frameworks and the Sustainable Energy Refugee Response Plan (SERRP) in the pipeline shall inevitably contribute to closing the sustainability vacuum in displacement camps - as the SERRP is geared towards alleviating the challenges of displaced communities with more resilient strategies.

\section{Challenges in Uganda's Displacement Camps}

\subsection{Inadequate Waste and Health Management}

Sanitation challenges due to poor solid waste and waste water disposal predominates most displacement camps in Uganda due to the ever - increasing refugee populations (Table 1) who reside in confined settlements $[17,18,23]$. The outcome has been adverse health conditions due to the strong inter linkage between poor sanitation and ill-health. Long before the current pandemic days, the health care systems in the refugee and host communities where already prone to adverse strain, mainly because of inadequate service delivery, human resource, financing and health commodities that could not sustainably match with the superseding refugee influx [21].

The situation therefore becomes more worrisome in the post pandemic era considering the pre-existing 1.5/1000/day child mortality deaths which were mainly due to malaria, respiratory and water borne diseases such as cholera [21]. Furthermore, due to the vast pressures exerted on the country health systems whose quality of services and reporting has already been in check, more significant challenges i.e. testing become apparent considering that measures such as social distancing are more difficult to implement to the bare minimum in these communities.

\subsection{Energy Constraints, Insecurity and Inequality}

The predominant source of energy in Ugandan displacement camps is fire wood (97\%) which is increasingly becoming both a scarce and an expensive resource [18]. In effect, the refugees are compelled to sell part of their reduced and dwindling food rations which is against the World Food Program's protocols in effort to raise money and buy firewood from the local markets that are strictly run by the host communities [20]. The practice of continued firewood usage with the three stone open fires for cooking is characterized categorically by in- and out-door air pollution which predisposes these communities to respiratory infections and health-related problems reported to be among the leading 
cause of illness and death in the refugee settlements [18, 21]. Respiratory infections could also lead to increased COVID-19 infections due to inaccurate diagnosis.

The pandemic continues to relentlessly affect women and girls in the displacement camps whose conventional task is to collect firewood. Due to severe deforestation in some of these camps, they are forced to travel long journeys of between 4-10 kilometers which further exposes them to Sexual and Gender Based Violence (SGBV) [10, 18]. Additionally, this significantly hinders participation in more developmental and productive activities.

\subsection{Unemployment and Food Insecurity}

The refugees in displacement camps are exposed to chronic vulnerabilities of unemployment which has retarded the CRRF objective of refugee self-reliance [24]. These marginalized settlements are deprived of economic stability due to exclusion regardless of Uganda having implemented a policy that promotes inclusion of refugees in socio-economic activities. Previously, the chances of informal employment were limited and more often not sustainable as existent businesses are established in marginalized areas prone to limited market availability [9].

With the COVID-19 pandemic, just as it is and continues to manifest in many countries globally, job losses, slowdown of business, drop in income levels and limited access to supplies to mention, shall disproportionately affect refugees owing to the several disruptions [14].

The practice of refugees selling their limited food rations as aforementioned, is mainly due to unemployment and fewer alternative income generating activities. Therefore, this trend of food insecurity is expected to increase exponentially among refugees due to the dwindling external support by donor agencies and concerned stakeholders as more resources have now been diverted to addressing the current COVID-19 crisis and many inadvertent pandemic induced shocks [10].

\section{Energy as an Enabler for ISD with Global Case Studies}

Energy access is deemed a prerequisite for attaining other SDGs as it contributes to 125 (i.e. $74 \%$ ) of the 169 SDG targets [13]. This is because it is beneficial in terms of health, education, gender equality, water supply, food security, environmental protection and sanitation among others. However, most displacement camps in Uganda are entirely dependent on non-sustainable energy resources i.e. biomass for cooking, heating and lighting which have adverse environmental and health impacts [10].

Over time, this has led to increasing contentions over the scarce resource - thus amplifying the energy crisis catastrophe. However, provision of renewable energy (RE) to the displaced communities helps to quickly spur socio-economic development in a more secure and sustainable manner [25]. Therefore in the wake of the COVID-19 pandemic, lasting energy solutions premised on sustainability, efficiency, equity and inclusion as fronted by the UNHCR Global Strategy for sustainable energy shall be of essence.

Waste generation in displacement camps continues to increase on a case by case basis though not given much emphasis with regards to its consideration for provision of waste management services [18]. It is from this perspective therefore, that energy recovery from waste options continues to gain ground with regards to their adoption in the displacement settings mainly because about $70 \%$ of the waste is organic [26].

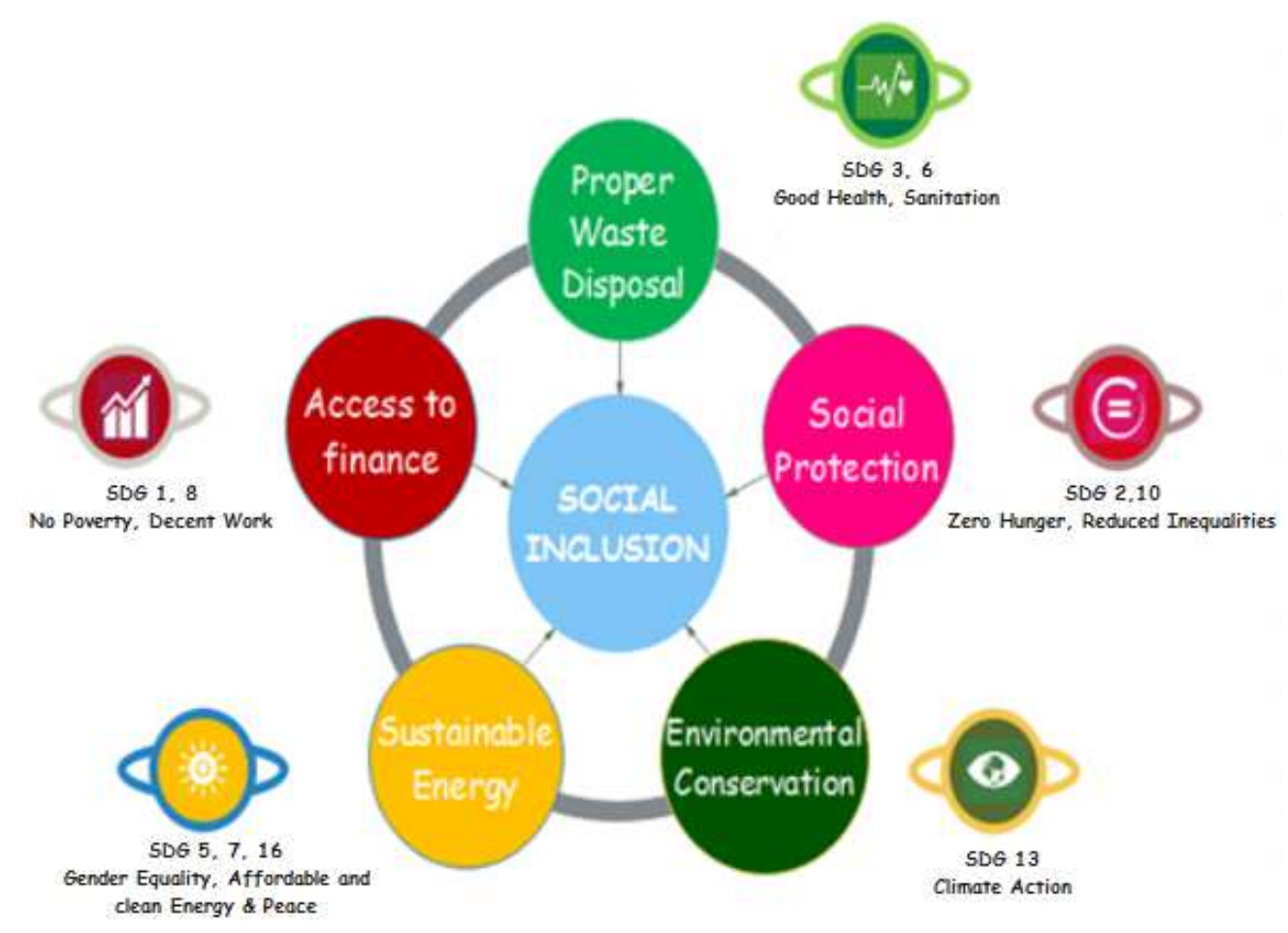

Figure 2. Challenges of socio-economic inclusion. Source: Authors. 
Since generated waste poses significant health and environmental challenges, the $\mathrm{WtE}$ technologies shall prove worthwhile as they are both developmental and humanitarian responses. Furthermore, the challenges of socio-economic inclusion (figure 2) can be resolved considerably as these technologies also help to fuel the local economy while also addressing waste management challenges.

Discussed below are some of the innovative solutions depicting the application of some $\mathrm{WtE}$ options that have been adopted and deployed in selected displacement camps around the world.

Case I: The Za'atari Syrian Refugee Camp (ZSRC) - Syria. Located in the Middle East 10 miles across the border from Syria in northern Jordan, the ZSRC is the seventh largest refugee camp in the world. The camp has a refugee population of about 77,534 and a per capita waste generation rate of $0.8 \mathrm{~kg} /$ day [27]. In order to solve the waste challenges faced in this camp, the study conducted by Al-addous et. al. eluded to the organic portion of the waste being $40-50 \%$ from which 81 and $16 \mathrm{~m}^{3}$ per ton of solid organic and sludge waste respectively was possible for improved hygiene and agricultural sustainability [27].

Case II: Bambasi Refugee Camp (BRC) - Ethiopia.

BRC is located west of Ethiopia and is home to over 20,000 refugees. It too, as a result of its poor waste management methods, the Norwegian Refugee Council (NRC) initiated a pilot biogas system to solve this challenge. Currently, this intervention is improving livelihoods in the camp by providing energy for both cooking as well as lighting. This has drastically led to reduced dependence on firewood for cooking while the freed up time is now invested in more income generating activities. Due to the existence of more families with cattle, plans for 19 additional biogas plants were underway to act as an integral approach for energy solutions in the camp [28].

Case III: Kutupalong Refugee Camp - Bangladesh.

Located in the far South East of Bangladesh in Cox's Bazar, the Rohingya refugees have kept streaming from neighboring Myanmar for over 20 years now. This overwhelming number of refugees necessitated an integrated approach in dealing with refugee health needs due to their increasing population. This influx led to the UNHCR initiative of founding the Cox's Bazar pilot biogas system in 2013, which treats the sewage sludge to reduce its contamination potential with the effluent used as a bio-fertilizer. Success of this pilot plant with proceeds of gas production rates of 0.6-2.5 litres per second [29] was obtained paving way for the construction of 22 more digesters.

The report by IRENA accentuated the most critical challenge of refugee settlements as access to sustainable, safe and affordable energy for cooking [25]. It is in this vein therefore that these proposed interventions respond to this global pursuit of ensuring that the energy needs of refugees and host communities are met more consciously and sustainably using RE technologies. These technologies shall account for 35\% of Uganda's WESRRP budget [17]. Whereas existent RE implementation models in rural communities of developing countries have been challenged by sustainability, the waste valorization preposition in this context is envisaged to be more adapted to progressively address systemic marginalization and exclusion through commercialization of $\mathrm{WtE}$ solutions that are further discussed in the subsequent section by piloting of blended subsidized fee and non-payment service business models.

In the post pandemic era, this shall serve as an augmented and pervasive effort for more improved resilience against the pandemic and its shocks so as to prevent the looming energy crisis with more certainty for improved ISD in this last decade of action.

\section{Sustainable WtE Options}

\subsection{Anaerobic Digestion}

Anaerobic Digestion (AD) is defined as a microbial degradation of organic material in the absence of oxygen. Usually, the process takes place in a reactor called a digester that can take the form of a fixed dome, floating drum or the balloon type [30]. During the AD process, biogas is generated and accumulates in a gas storage tank. This gas mainly contains methane $(\sim 60 \%)$, carbon dioxide $(\sim 40 \%)$ and some other constituent gases though in smaller quantities. Methane is the component of biogas that is combustible and as such is a potential fuel for cooking, heating, lighting and electricity generation [19]. Biogas can be generated from a wide range of organic materials which among others is solid organic waste. Using organic waste as feedstock for biogas generation also benefits the environment as it contributes to sanitation and reduction of GHG emission from the waste sector [18].

\subsection{Briquette Production}

Briquetting is a process that involves the conversion of waste into uniformly shaped blocks (briquettes) which are easier to transport, store and use for cooking or heating. This is done through a compaction process (by aid of a briquette machine) where pre-treated combustible material is mixed with a binder to form the briquettes that burn with a soot-less flame. This waste is inclusive of agricultural (specific), charcoal dust and household waste [18]. Briquettes have a high density and calorific value of more than 22MJ which can well be manufactured from locally available waste materials [31]. Briquettes can have a positive impact on these communities through creating local production and supply value chains thereby reducing the dependence on firewood and charcoal while providing employment and improving their socio-economic welfare.

\subsection{Incineration with Energy Recovery}

Incineration is a thermal controlled treatment process that involves subjection of mixed and untreated combustible matter to a high temperature treatment process (above $850^{\circ} \mathrm{C}$ ) that proceeds with energy generation and ash. Incineration is 
done in furnaces and usually requires the combustion of different types of waste material inclusive of organic, food, paper and cardboard though plastics and non-biodegradable waste are considered hazardous [30]. This technology is mainly practiced in areas where there is low land availability, increasing costs related to the treatment of large volumes of waste and robust environmental legislation related to waste disposal. Combustion yields to electricity and heat from large waste volumes though application in refugee settings may be deemed unsuitable [26].

\subsection{Gasification and Pyrolysis}

These technologies have collectively been termed as Advanced Thermal Treatment (ATT) processes that utilize elevated temperatures in conversion of waste material to produce syngas, coke, pyrolysis oil and char. Considered as being more competitive than incineration, this technology utilizes high temperature combustion (above $700^{\circ} \mathrm{C}$ ) at controlled oxygen conditions to reduce large waste volumes whilst destroying toxic waste products [32]. These technologies also utilize a wide variety of waste streams inclusive of plastic and several types of biodegradable wastes.

\subsection{Landfill with Gas Extraction}

The production of landfill gas (LFG) from organic waste provides a better solution to open and controlled burning as well as sanitary landfills by acting as an oversized anaerobic digester which was previously discussed (Section 6.1). It provides the opportunity of alleviating GHGs - the major contributing factor to global warming. Though it produces fuels with a lower methane content i.e. $40-50 \%$, this technology is also suitable for generation of heat and power. As a precaution however, proper consideration should be ensured not to incorporate slow digesting organics as they tend to reduce the methane yield [32].

\section{Evaluation of Sustainable WtE Options Using Multi Criteria Decision Analysis (MCDA)}

\subsection{Criteria for Analysing WtE Technology Options}

Table 2. Preference ranking for the individual factors/ criteria.

\begin{tabular}{|c|c|c|}
\hline No. & Criteria, $\mathbf{j}$ & Preferences (not significant-1, less significant-2, significant-3, more significant-4, extremely significant-5) \\
\hline 1. & Socio-economic benefits (A) & Increased productivity (5), safety and health (4), employment (3), reduced inequality (2), sanitation (1). \\
\hline 2. & Technology Sustainability (B) & $\begin{array}{l}\text { Availability of local expertise (5), feedstock availability (4), technology maturity (3), ease of operation and } \\
\text { maintenance of the technology (2), local acceptance of the technology (1). }\end{array}$ \\
\hline 3. & Cost of the technology $(\mathrm{C})$ & Affordability $\{$ low cost (5), moderate (4), average (3), expensive (2), extremely expensive (1) \} \\
\hline 4. & $\begin{array}{l}\text { Policy \& Regulatory } \\
\text { Frameworks (D) }\end{array}$ & $\begin{array}{l}\text { Supporting energy policy (5), ease of permit processing (4), monitoring compliance (3), Institutional capacity } \\
\text { (2), safety and environmental standards (1). }\end{array}$ \\
\hline
\end{tabular}

For this analysis, the above sustainable WtE technology options where assessed based on five factors (Table 2) i.e. the socio-economic benefits (A), technology sustainability (B), cost of technology (C), policy and regulatory frameworks (D), and environmental sustainability (E) adapted from the decision makers guide developed by the GIZ [32].

Based on the authors [31,32], the individual costs of each technology comprising of the capital, operation and maintenance $(\mathrm{O} \& M)$ and their individual summations were considered as shown in table 3 below.

Table 3. Individual technology costs.

\begin{tabular}{llllll}
\hline Costs ((EUR/t) & AD [32] & Briquetting* [31] & Incineration [32] & Gasification \& Pyrolysis [32] & LFG [32] \\
\hline Capital & 1.6 & 0.06 & 38.5 & 40 & 1.4 \\
O \& M & 13.5 & 0.509 & 27.5 & 35 & 75 \\
Total & 29.5 & 0.569 & 66 & 0.3 \\
\hline
\end{tabular}

* Cost break down based on household level

NB: EUR/t - Euros per ton.

\subsection{Rating of the WtE Technology Options.}

These technology options $(i)$ were independently scored $\left(S_{i j}\right)$ with respect to the individually ranked preferences against the set criteria $(j)$. This logical scoring principle based on the local Ugandan context yielded to particular individual ratings of these technologies as highlighted in table 4 below. 
Table 4. Rating of WtE Technology Options by scoring.

\begin{tabular}{llllll}
\hline & & & Criteria, $\mathbf{j}$ & \\
\cline { 2 - 5 } & A & B & C & D & E \\
\hline Technological Options, $i$ & & & Scores, Sij & & \\
AD & 11 & 12 & 3 & 11 & 12 \\
Briquetting & 10 & 13 & 5 & 8 & 10 \\
Incineration & 9 & 7 & 2 & 6 & 9 \\
Gasification \& Pyrolysis & 8 & 7 & 1 & 9 & 9 \\
LFG & 7 & 8 & 4 & 7 & 7 \\
\hline
\end{tabular}

Table 5. Rating of WtE Technology options using the weighting method.

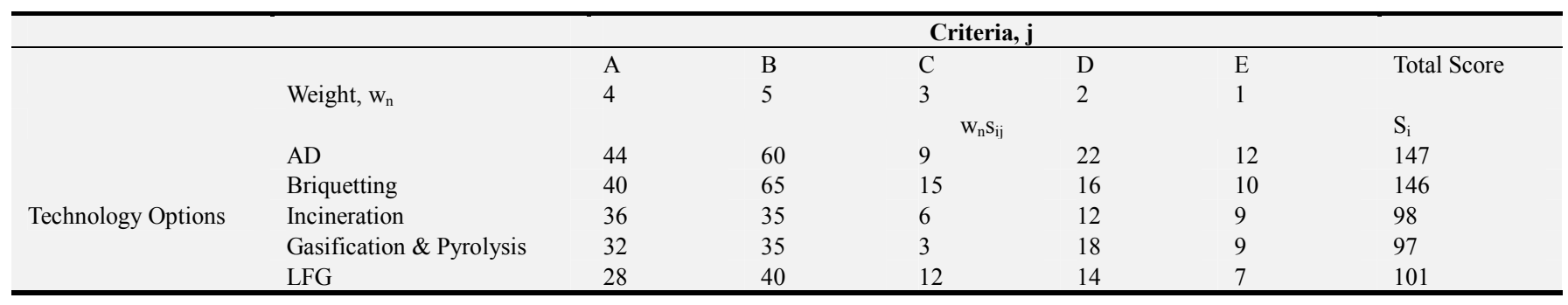

To determine the overall weighted score for each technology option, the expression (1) below as suggested by DCLG was considered and the results shown in table 5 [33].

$$
\mathrm{S}_{\mathrm{i}}=\mathrm{w}_{1} \mathrm{~s}_{\mathrm{i} 1}+\mathrm{w}_{2} \mathrm{~s}_{\mathrm{i} 2}+\ldots+\mathrm{w}_{5} \mathrm{~s}_{\mathrm{i} 5}=\sum_{j=1}^{n} w_{i} s_{i j}
$$

With consideration of different tradeoffs, the MCDA tries to help attain coherence in decision making. The total score $\left(S_{i}\right)$ in the last column (Table 5) captures the objective measure of the different technology options which were assessed based on the Ugandan scenario using the aforementioned criteria. From the analysis, anaerobic digestion closely followed by briquetting had the highest scores (147 and 146 respectively) mainly because the costs of the technologies are lower; easier to maintain and operate using locally available resources and technical expertise to mention.

It can be clearly seen that the most advanced WtE technologies have lower scores despite having many socio-economic benefits mainly because of high capital costs; high operation and maintenance costs; lack of locally available technical expertise and the level of technological acceptance. Interestingly, since LFG had the second lowest total cost of operation i.e. $1.7 \mathrm{EURO} / \mathrm{ton}$ it ranked third against its competitive advanced technologies. Therefore, for quick intervention in regard to the threat caused by the energy crisis in the Ugandan displacement camps, it is imperative of the government and the financial stakeholders to employ anaerobic digestion and briquetting while considering other technologies in the order of LFG, incineration and gasification and pyrolysis as long term interventions in the post-covid-19 sustainable energy recovery plan.

\section{Recommendations}

Since localization of the global SDGs is at the fore front of meeting specific national targets as earlier on set out in several existing policies and plans, more inclusive endeavors, solidarity and political will with respect to the displaced communities shall be key in order to provide leverage between the prevailing pandemic and the energy crisis for shared socio economic sustainable development. This calls for recommendations such as; the establishment of a sustainable energy strategy for the displaced, conducting energy needs assessment for individual camps, developing technology guidelines and standards and fast track the development of the SERRP. In particular, advanced interventions towards cost-effective technologies especially AD as evidenced by the MDCA shall prove worthwhile. The setting out of inherent indicators and targets towards $\mathrm{AD}$ shall provide more transformative pathways within this decade of action timeframe. This shall pave way for more inclusivity and sustainable socio economic development in a more reliable, secure, efficient and environmentally protective manner for the refugee community.

\section{Conclusion}

Accelerating inclusive sustainable development in the post COVID-19 era shall not only necessitate the prioritization of the health sector but also tackling of the looming energy crisis in displaced communities which are amongst the most vulnerable populations in the wake of this pandemic whose consequences are going to be far reaching. These energy concerns have been strongly spelt out in the UN Agenda 2030, Uganda Vision 2040, NDPIII and several other policy frameworks. Prompt implementation should take a form that is indiscriminative of the marginalized, displaced and the disproportionately poor populations. With particular emphasis placed on the displaced whose population magnitudes continue to proliferate, fronting energy access in the form of waste valorization through mainly anaerobic digestion and briquetting shall inevitably promote inclusivity and sustainable development among the five analyzed technologies. This is mainly so as the above best ranked technologies (anaerobic digestion and briquetting) also are consistent the current WESRRP. 


\section{Acknowledgements}

The authors extend sincere gratitude to the German Academic Exchange Service (DAAD) for sponsoring this research.

\section{References}

[1] UN, (2020). The Sustainable Development Goals Report 2020, United Nations, New York.

[2] A. Ntale, (2019). Progress on Implementation of Sustainable Development Goal 8 on Decent Work and Economic Growth in Uganda (2019), Akina Mama wa Afrika, Hivos.

[3] NPA, (2015). National Development Plan II, 2015/16 2019/20, National Planning Authority.

[4] K. Urama, N. Ozor, E. Acheampong, (2014). Achieving Sustainable Development Goals (SDGs) Through Transformative Governance Practices and Vertical Alignment at the National and Subnational Levels in Africa, SDplanNet Africa Secretariat.

[5] NPA, (2020). Third National Development Plan (NDPIII) 2020/21 - 2024/25, National Planning Authority. Government of Uganda.

[6] OPM, (2020). The Second Voluntary National Review Report on the Implementation of the 2030 Agenda for Sustainable Development, Office of the Prime Minister. Republic of Uganda.

[7] UNHCR, (2019). Global Trends: Forced Displacement in 2018, United Nations High Commissioner for Refugees, Geneva.

[8] UNHCR, (2021). Uganda Comprehensive Refugee Response Portal as of 1 March 2021, Geneva: UNHCR.

[9] H. Bohnet, S.-P. Clara, (2019). Uganda: A Role Model for Refugee Integration?, (BICC Working Paper, 2/2019). Bonn: Bonn International Center for Conversion (BICC).

[10] UNHCR, (2020). Revised Uganda Country Refugee Response Plan, United Nations High Commissioner for Refugees, Geneva.

[11] UNHCR, (2021). Refugees and Asylum-Seekers in Uganda as of 25 February 2021.

[12] UNHCR, (2018). Two Year Progress Assessment of the CRRF Approach, United Nations High Commissioner for Refugees, Geneva. Switzerland.

[13] UNHCR, (2019). Global Strategy for Sustainable Energy, United Nations High Commissioner for Refugees, Switzerland.

[14] A. Atamanov, N. Yoshida, T. Beltramo, R. Rivera, I. Sarr, P. Waita, K. Yoshimura, (2021). Monitoring Social and Economic Impacts of COVID-19 on Refugees in Uganda: Results from the High-Frequency Phone Survey, World Bank, UNHCR and UBOS.

[15] UNHCR, (2020). Uganda Comprehensive Refugee Response Portal as of 29 February 2020, Geneva: UNHCR.
[16] URN, (2020). South Sudan Refugees Enter Uganda despite Border Closure - Daily Monitor. Retrieved on 2 April, 2020.

[17] MWE, (2019). Water and Environment Sector Response Plan for Refugees and Host Communities in Uganda, Ministry of Water and Environment. Uganda.

[18] UNHCR, (2016). Safe Access to Fuels and Energy Strategy, 2016-2020., United Nations High Commissioner for Refugees. Uganda.

[19] UNEP ISWA, (2015). Global Waste Management Outlook, United Nations Environment Programme, International Solid Waste Association.

[20] R. L. Miller, M. A. Ulfstjerne, (2020). Energy Res. Soc. Sci. 63, $1-10$.

[21] MoH, (2019). Health Sector Integrated Refugee Responce Plan 2019-2024, Ministry of Health. Government of Uganda.

[22] N. Crawford, S. O. Callaghan, K. Holloway, C. Lowe, (2019). The Comprehensive Refugee Response Framework: Progress in Uganda, Humanitarian Policy Group, Overseas Development Institute.

[23] UNEP OCHA JEU, (2019). Bidibidi Refugee Settlement: Environmental Scoping Report and Recommendations, United Nations Environment Program, United Nations Office for the Coordination of Humanitarian Affairs \& Joint Environment Unit.

[24] A. Vogelsang, (2017). Local Communities' Receptiveness to Host Refugees: A Case Study of Adjumani District in Times of a South Sudanese Refugee Emergency, M. Arts Thesis, Utrecht University.

[25] IRENA, (2019). Renewables for Refugee Settlements: Sustainable Energy Access in Humanitarian Situations, International Renewable Energy Agency, Abu Dhabi.

[26] UNHCR, (2015). WASH Manual: Solid Waste Management, United Nations High Commissioner for Refugees, Geneva.

[27] M. Al-addous, M. N. Saidan, M. Bdour, M. Alnaief, (2018). Energies 12, 1-11.

[28] UNHCR, (2018). Bambasi Refugee Camp, United Nations High Commissioner for Refugees. Ethiopia.

[29] J. Eyrard, A. Girard, K. Alome, (2015). 38th WEDC Int. Conf. Loughbrgh. Univ. UK, pp. 1-5.

[30] H. I. Abdel-shafy, M. S. M. Mansour, (2018). Egypt. J. Pet. 27, $1275-1290$.

[31] D. Hakspiel, A. Foote, J. Parker, (2018). Container-Based Toilets with Solid Fuel Briquettes as a Reuse Product: Best Practice Guidelines for Refugee Camps, UNHCR, Sanivation and Bill \& Melinda Gates Foundation.

[32] D. Mutz, D. Hengevoss, C. Hugi, T. Gross, (2017). Waste-to-Energy Options in - Municipal Solid Waste Management, Deutsche Gesellschaft für Internationale Zusammenarbeit (GIZ) GmbH.

[33] DCLG, (2009). Multi-Criteria Analysis: A Manual, Department for Communities and Local Government: London. 